\title{
RESEARCH
}

Open Access

\section{Hypoxia-preconditioned adipose-derived stem cells combined with scaffold promote urethral reconstruction by upregulation of angiogenesis and glycolysis}

Xiang Wan $^{\dagger}$, Min-kai Xie ${ }^{\dagger}$, Huan Xu', Zi-wei Wei, Hai-jun Yao, Zhong Wang ${ }^{*}$ and Da-chao Zheng ${ }^{*}$ (D)

\begin{abstract}
Rationale: Tissue engineering is a promising alternative for urethral reconstruction, and adipose-derived stem cells (ADSCs) are widely used as seeding cells. Hypoxia preconditioning can significantly enhance the therapeutic effects of ADSCs. The low oxygen tension of postoperative wound healing is inevitable and may facilitate the nutritional function of ADSCs. This study aimed to investigate if hypoxia-preconditioned ADSCs, compared to normoxiapreconditioned ADSCs, combined with scaffold could better promote urethral reconstruction and exploring the underlying mechanism.
\end{abstract}

Methods: In vitro, paracrine cytokines and secretomes that were secreted by hypoxia- or normoxia-preconditioned ADSCs were added to cultures of human umbilical vein endothelial cells (HUVECs) to measure their functions. In vivo, hypoxia- or normoxia-preconditioned ADSCs were seeded on a porous nanofibrous scaffold for urethral repair on a defect model in rabbits.

Results: The in vitro results showed that hypoxia could enhance the secretion of VEGFA by ADSCs, and hypoxiapreconditioned ADSCs could enhance the viability, proliferation, migration, angiogenesis, and glycolysis of HUVECs $(p<0.05)$. After silencing VEGFA, angiogenesis and glycolysis were significantly inhibited $(p<0.05)$. The in vivo results showed that compared to normoxia-preconditioned ADSCs, hypoxia-preconditioned ADSCs combined with scaffolds led to a larger urethral lumen diameter, preserved urethral morphology, and enhanced angiogenesis $(p<$ 0.05).

Conclusions: Hypoxia preconditioning of ADSCs combined with scaffold could better promote urethral reconstruction by upregulating angiogenesis and glycolysis. Hypoxia-preconditioned ADSCs combined with novel scaffold may provide a promising alternative treatment for urethral reconstruction.

Keywords: Hypoxia, Adipose-derived stem cells, Angiogenesis, Glycolysis, Urethral, Tissue engineering

\footnotetext{
*Correspondence: zhongwang2000@sina.com; zhengdachao@126.com

${ }^{+}$Xiang Wan, Min-kai Xie and Huan Xu contributed equally to this work. Department of Urology, Shanghai Ninth People's Hospital, Shanghai Jiao Tong University School of Medicine, No.639, Zhizaoju Road in Huangpu District, Shanghai 200011, China
}

C C The Author(s). 2020 Open Access This article is licensed under a Creative Commons Attribution 4.0 International License, which permits use, sharing, adaptation, distribution and reproduction in any medium or format, as long as you give appropriate credit to the original author(s) and the source, provide a link to the Creative Commons licence, and indicate if changes were made. The images or other third party material in this article are included in the article's Creative Commons licence, unless indicated otherwise in a credit line to the material. If material is not included in the article's Creative Commons licence and your intended use is not permitted by statutory regulation or exceeds the permitted use, you will need to obtain permission directly from the copyright holder. To view a copy of this licence, visit http://creativecommons.org/licenses/by/4.0/ The Creative Commons Public Domain Dedication waiver (http://creativecommons.org/publicdomain/zero/1.0/) applies to the data made available in this article, unless otherwise stated in a credit line to the data. 


\section{Introduction}

A variety of diseases, such as congenital diseases, malignancies, and trauma, can lead to anterior urethral defects or strictures, which severely influence the physical condition and quality of life of patients [1]. Buccal mucosa and penile skin are the most popular tissues used to repair urethral defects in the clinic. However, donor site morbidity, limited supply of materials, and complications, such as urethrocutaneous fistula and restenosis, hinder the further clinical application of these tissues [2]. Many studies have demonstrated that cell-seeded biomaterials might be an effective method and show great promise in urethral reconstruction $[3,4]$.

Adipose-derived stem cells (ADSCs) are widely used in regenerative medicine [5]. Increasing evidence has demonstrated that trophic and paracrine functions, rather than multipotency, account for the therapeutic benefits of ADSCs [6]. Various growth factors and bioactive cytokines are released to stimulate the growth of nearby cells by paracrine signaling [7, 8]. For this reason, recent studies have focused on how to increase the paracrine activities of stem cells to improve angiogenesis and blood flow recovery for tissue regeneration $[9,10]$.

On the one hand, ADSCs are more adapted to hypoxia, and under hypoxia preconditioning, these cells can enhance their paracrine activity, proliferation, and survival $[11,12]$. ADSCs reside in an environment with a relatively low oxygen level between 1 and 5\%, which is significantly lower than the oxygen level required by other cells (i.e., $20-21 \% \mathrm{O}_{2}$ ) [13]. For example, previous studies in a hindlimb ischemia model showed that adapting ADSCs by hypoxia preconditioning improves angiogenesis, accelerates tissue regeneration, and improves blood perfusion [14]. On the other hand, postoperative ischemia and hypoxia are inevitable and may lead to poor prognosis [15]. The microenvironment of the early period of tissue damage, wound recovery, or tissue engineering repair is characterized by ischemia and low oxygen tension [16]. Compared to other cells, ADSCs that reside in "naturally hypoxic conditions" could better survive and adapt to this condition and secrete more paracrine therapeutic factors, including vascular endothelial growth factor-A (VEGF-A). It is plausible that this characteristic of stem cells may be applied to repairing damaged tissue and facilitating tissue regeneration $[17,18]$.

Angiogenesis plays a significant role in fracture healing, tissue regeneration, and tissue engineering [19]. Angiogenesis provides nutrients, oxygen, and growth factors and removes metabolic waste. The formation of vessels is inextricably linked with the metabolic state [20]. Interestingly, vessel endothelial cells are highly dependent on glycolysis rather than oxidative phosphorylation; approximately $90 \%$ of adenosine triphosphate
(ATP) in these cells is generated by glycolysis [21]. Vessel endothelial cells are highly dependent on glycolysis for ATP production, and the inhibition of glycolytic activators in vessel endothelial cells leads to vascular hypobranching [22]. VEGF is one of the most important cytokines for angiogenesis that is secreted by hypoxiapreconditioned ADSCs, and it exerts a significant influence on endothelial cells during vascularization [23]. Hypoxia-preconditioned ADSCs secreted more VEGF, as determined by enzyme-linked immunosorbent assay (ELISA) assay [17].

In our previous study, we fabricated a porous bilayered nanofibrous scaffold using a PLLA/PCL/PLGA blend. This heterogeneous, porous, bilayered, nanofibrous graft closely mimics the microstructure of the extracellular matrix (ECM) and has two sides: the inner surface with a small pore size can prevent the infiltration of urine to internal cells or transplanted cells, and it can also facilitate the confluence of urethral epithelial cells on the lumen; the outer surface with a larger pore size provides adequate space for the infiltration and regeneration of blood vessel cells and smooth muscle cells [24-26].

The underlying mechanism by which ADSCs facilitate angiogenesis is not currently completely understood [27]. We hypothesized that hypoxia-preconditioned ADSCs could secrete more paracrine cytokines, such as VEGF, to enhance the proliferation of vessel endothelial cells by upregulating glycolysis during urethral reconstruction. To address this hypothesis, in an in vitro study, we used paracrine cytokines and secretomes that were secreted by hypoxia- or normoxia-preconditioned ADSCs to treat human umbilical vein endothelial cells (HUVECs), and we observed the viability, proliferation, migration, angiogenesis, and metabolic state of the HUVECs. In an in vivo study, we evaluated the ability of hypoxia- or normoxia-preconditioned ADSCs that were transplanted onto our bilayered nanofibrous scaffold to repair urethral defects in a rabbit model by hematoxylin and eosin (H\&E) staining, immunofluorescence staining, and urethrography.

\section{Materials and methods Ethical approval}

All animal procedures were approved by the Animal Ethics Committee of Shanghai University of Traditional Chinese Medicine (Reference no: P2SHUTCM200424005) and carried out in accordance with the guidelines for the National Institutes of Health Guide for the Care and Use of Laboratory Animals.

\section{Cell isolation and culture}

ADSCs were separated from inguinal adipose tissue. The 15 rabbits $(2.5-3.5 \mathrm{~kg})$ were subjected to general anesthesia by intravenous injection of sodium pentobarbital. The 
adipose tissues were isolated from the bilateral inguinal region followed by rinsing with $0.25 \%$ chloromycetin in sterilized PBS. The tissue was homogenized and digested in $50 \mathrm{ml} 0.1 \%$ type IV collagenase (S1745401, Nordmark Biochemicals, Germany) for $50 \mathrm{~min}$ at $37^{\circ} \mathrm{C}$ with sustained oscillations. After digestion, the solution was centrifuged at $800 \mathrm{rpm}$ for $10 \mathrm{~min}$. The supernatant was discarded, and the precipitate was mixed with sterilized PBS. After filtration with a cell strainer (Falcon, USA), the mixture was centrifuged at $1000 \mathrm{rpm}$ for $5 \mathrm{~min}$. After discarding the supernatant, the precipitate was resuspended in $\alpha$-modified Eagle's medium ( $\alpha$-MEM) (HyClone, Logan, UT, USA) supplemented with $10 \%$ fetal bovine serum (FBS, Gibco) and $1 \%$ Antibiotic-Antimycotic (Gibco, USA) in a $10-\mathrm{cm}$ cell culture dish. The cell culture dishes were placed in a humidified incubator at $37{ }^{\circ} \mathrm{C}$ with $5 \%$ carbon dioxide. We changed the culture medium every $48 \mathrm{~h}$ and passaged the ADSCs when they reached $80 \%$ confluence. The 15 rabbits were used in subsequent experiments. The isolated stem cells are for each rabbit's own use. HUVECs were separated from the umbilical cord and cultured in endothelial cell medium (ScienCell, USA) supplemented with 10\% FBS (Gibco, USA) and 1\% penicillin and streptomycin (Gibco, USA). The ADSCs and HUVECs were cultured in a humidified incubator with $5 \% \mathrm{CO}_{2}$ at $37^{\circ} \mathrm{C}$.

\section{Identification of ADSCs}

The identification of ADSCs was conducted by evaluating their adipogenic, osteogenic, and chondrogenic differentiation potential. The adipogenic differentiation, osteogenic differentiation, and chondrogenic differentiation of the ADSCs were conducted strictly in accordance with the manufacturer's instructions (Cyagen, USA). The results of adipogenesis, chondrogenesis, and osteogenesis were identified by Oil Red O, Alizarin Red, and Alcian Blue staining (Cyagen, USA).

\section{Hypoxic cell culture}

When ADSCs at passage 3 reached 70\% confluence, the $10-\mathrm{cm}$ plate was washed with sterilized PBS, and $10 \mathrm{ml}$ $\alpha$-MEM without FBS was added. The plates were cultured under normoxic $\left(21 \% \mathrm{O}_{2}\right)$ or hypoxic $\left(1 \% \mathrm{O}_{2}\right)$ conditions for 2 days. After filtration, the conditioned medium was added to a centrifugal filter unit with a 3kDa cutoff (Millipore, Bedford, MA, USA). The centrifugal filters were centrifuged at $3000 \mathrm{rpm}$ to concentrate the medium by 50 -fold. The concentrated hypoxia- or normoxia-conditioned medium was mixed with FBS-free endothelial cell medium at a ratio of 1:3 and was labeled as solution $\mathrm{H}$ or solution $\mathrm{N}$.

\section{Cell proliferation assays}

The effects of secreted fractions from hypoxia- or normoxia-preconditioned ADSCs on the proliferation of the HUVECs were tested by a Cell Counting Kit-8 (CCK-8; Dojindo, Kumamoto, Japan) according to the manufacturer's instructions. Briefly, 1000 HUVECs/well were seeded in a 96-well plate. The HUVECs were cultured by solution $\mathrm{H}$ or $\mathrm{N}$ and labeled as group $\mathrm{H}$ and $\mathrm{N}$. At $0,12,24$, and $48 \mathrm{~h}$ of culture, $10 \%$ CCK- 8 reagent was mixed with medium and added to each well. The 96-well plate was incubated at $37^{\circ} \mathrm{C}$ for $1 \mathrm{~h}$. The relative number of cells was measured by absorbance at $450 \mathrm{~nm}$ using a microplate reader (BioTek, USA).

\section{Colony formation assays}

The HUVECs were seeded in a 6-well plate at 500 cells/ well. The cells were treated with solution $\mathrm{H}$ or $\mathrm{N}$ and were labeled as group $\mathrm{H}$ and $\mathrm{N}$. The medium was changed every 3 days. Fourteen days later, the cells were fixed with $4 \%$ paraformaldehyde and stained with crystal violet solution for 6-10 min. Groups consisting of 50 or more cells were scored as colonies. The results were derived from three repeated experiments.

\section{Flow cytometry}

Flow cytometric detection was carried out to evaluate the effects of secreted fractions from hypoxia- or normoxia-preconditioned ADSCs on the cell cycle and apoptosis of HUVECs. For the cell cycle analysis, the HUVECs were treated with solution $\mathrm{H}$ or $\mathrm{N}$ for $24 \mathrm{~h}$, washed twice with sterile PBS, and fixed in $70 \%$ ice-cold ethanol. The mixture was stored at $4{ }^{\circ} \mathrm{C}$ overnight for further use. The HUVECs were treated with a mixture of $25 \mu \mathrm{l}$ propidium iodide and $20 \mu \mathrm{l}$ RNaseA at $37^{\circ} \mathrm{C}$ for $0.5 \mathrm{~h}$. The mixture was analyzed with flow cytometry (BD Biosciences Inc., NJ, USA). After the induction of apoptosis, the HUVECs were harvested and resuspended in $300 \mu \mathrm{l}$ binding buffer supplemented with $5 \mu \mathrm{l}$ Annexin V-FITC. The mixture was stored in the dark at $4{ }^{\circ} \mathrm{C}$ for $0.5 \mathrm{~h}$, and then, $5 \mu \mathrm{l}$ PI was added for $5 \mathrm{~min}$. The outcome was analyzed with FACSDiva Software (BD Bioscience). The necrotic cells, late-stage apoptotic cells, early apoptotic cells, and live cells were identified as $\mathrm{V}$ FITC-/PI+ (upper left quadrant), Annexin V-FITC+/PI+ (upper right quadrant), Annexin V-FITC+/PI- (lower right quadrant), and Annexin V-FITC-/PI- (lower left quadrant), respectively.

\section{Cell migration assay}

To evaluate the effect of secreted fractions from hypoxia- or normoxia-preconditioned ADSCs on the migration of HUVECs, we performed wound healing assays and transwell migration assays.

For the wound healing assay, the HUVECs were seeded in a 6-well plate as a monolayer. A sterile $200-\mu \mathrm{l}$ pipette tip was used to scratch a straight line. Then, solutions $\mathrm{H}$ or $\mathrm{N}$ were applied. Images were obtained at 
$24 \mathrm{~h}$ and analyzed. The results were derived from three repeated experiments.

For the transwell migration assay, $1.0 \times 10^{5}$ cells were seeded in the upper chamber of transwell 24well plates (Corning, USA). The plate included $8-\mu \mathrm{m}$ pores for cell migration. After $12 \mathrm{~h}$, the media in the lower chambers of the 24-well plates were replaced with solution $\mathrm{H}$ or $\mathrm{N}$. After $12 \mathrm{~h}$, the cells in the upper chamber were removed by a cotton swab, and the cells on the membrane were stained with $0.1 \%$ crystal violet solution (Sigma-Aldrich). The results were analyzed by ImageJ software.

\section{Angiogenic-related assessment}

The levels of VEGF, hepatocyte growth factor (HGF), and fibroblast growth factor (FGF) that were secreted by hypoxia- or normoxia-preconditioned ADSCs were tested by enzyme-linked immunosorbent assay (ELISA). When the ADSCs reached 80-90\% confluence, they were washed with sterile PBS and cultured under hypoxic $\left(1 \% \mathrm{O}_{2}\right)$ or normoxic $\left(21 \% \mathrm{O}_{2}\right)$ conditions. After 2 days of culture, the supernatant was concentrated and measured by ELISA kits (VEGF: ab100663, FGF: ab99979, and HGF: ab100534, Abcam, UK) according to the manufacturer's instructions. The results were derived from three repeated experiments.

The expression of VEGFR2, the key receptor of VEGFA, was tested by Western blotting (WB) and quantitative real-time polymerase chain reaction (RT-qPCR). The HUVECs were cultured in solution $\mathrm{H}$ or $\mathrm{N}$ for $24 \mathrm{~h}$ and labeled as groups $\mathrm{H}$ and $\mathrm{N}$. The cells were lysed with lysis buffer, and the protein concentration was measured with a BCA kit. Fifty micrograms of protein was acquired from groups $\mathrm{H}$ and $\mathrm{N}$, resolved by SDS-PAGE, and transferred to PVDF membranes. After blocking with $5 \%$ skim milk, the membranes were incubated with primary antibodies against VEGFR2 (ab39638, Abcam). After overnight incubation at $4{ }^{\circ} \mathrm{C}$, the membranes were incubated with secondary antibodies for $1 \mathrm{~h}$. After incubation, the membranes were exposed and photographed. The data were analyzed by Quantity One software (Hercules). The mRNA of VEGFR2 was measured with RT-qPCR. After the cells were cultured with solution $\mathrm{H}$ or $\mathrm{N}$ for $24 \mathrm{~h}$, the total RNA was extracted from the HUVECs by TRIzol Reagent (Invitrogen, USA) according to the manufacturer's protocol. cDNA was synthesized using a Reverse Transcription Kit (Takara, Japan). The primers and cDNA were added to the SYBR Green PCR master mix (Takara, Japan) according to the manufacturer's protocol. GAPDH was chosen as the internal control. All the primer sequences are listed in Table S1.

The angiogenic activity of hypoxia- or normoxiapreconditioned ADSCs was assessed by tube formation assay. A 24-well plate was precoated with Matrigel (BD
Biosciences, San Jose, CA, USA) for $24 \mathrm{~h}$. HUVECs $(1.5 \times$ $10^{5}$ ) were harvested and seeded in each well, cultured in solutions $\mathrm{H}$ or $\mathrm{N}$, and labeled as groups $\mathrm{H}$ and $\mathrm{N}$. After $10 \mathrm{~h}$ of incubation at $37^{\circ} \mathrm{C}$, capillary formation was observed by phase-contrast microscopy (Olympus, Japan). The outcome was analyzed by Image-Pro Plus 6.0 software (Media Cybernetics, Inc., MD, USA).

\section{Metabolic activity assays}

The effect of hypoxia- or normoxia-preconditioned ADSCs on the metabolic activity of HUVECs was evaluated by measuring the mRNA and protein expression levels of hypoxia-inducible factor- $1 \alpha$ (HIF-1 $\alpha$ ) (NB100105, Novus) and hexokinase 2 (HK2) (Cell Signaling, Cst \#2867). HUVECs were cultured in solution $\mathrm{H}$ or $\mathrm{N}$ for $24 \mathrm{~h}$, which were labeled as groups $\mathrm{H}$ and $\mathrm{N}$, and the total protein and mRNA were extracted and assessed by WB and RT-qPCR. The detailed procedure is described above.

\section{Transfection of siRNA}

Small interfering RNA (siRNA) were transfected according to the manufacturer's protocol (GenePharma Co, Shanghai, China). The ADSCs were cultured in FBS-free medium $30 \mathrm{~min}$ before the siRNA transfection. Then, 100 pmol of si-VEGF or si-Control was transiently transfected by Lipofectamine 2000. The medium was changed to complete medium $6 \mathrm{~h}$ later. The content of secreted VEGFA was measured by ELISA. si-VEGF or si-Control + hypoxia-preconditioned and si-VEGF or si-Control + normoxia-preconditioned ADSCs were used to treat HUVECs. The mRNA and protein expression levels of VEGFR2, HIF-1 $\alpha$, and HK2 were determined. The tube formation assay was performed to determine the angiogenic activity.

\section{Fabrication of porous, bilayered, nanofibrous scaffolds}

The fabrication of the scaffold was previously described [25]. Briefly, the microporous inner layer was fabricated by a poly L-lactic acid (PLLA)/poly lactic-co-glycolic acid (PLGA)/poly L-lactide-co-e-caprolactone (PLCL) blend with a ratio of 20:20:60 using the thermally induced phase separation (TIPS) technique. Next, a PLLA/PLGA/poly caprolactone (PCL) blend with a ratio of 30:40:30 was cast onto the surface of the microporous inner layer. After separation, solvent exchange, and freeze-drying, the scaffold was obtained.

\section{Seeding ADSCs on scaffolds and identification}

ADSCs were seeded on the scaffold and identified by scanning electron microscopy (SEM), immunohistochemistry (IHC), and confocal laser scanning microscopy (CLSM). 
Before seeding, the scaffold was immersed in $75 \%$ alcohol for $48 \mathrm{~h}$ and washed 3 times with sterilized distilled water. Then, the scaffold was treated with ultraviolet rays overnight to prepare for the seeding of ADSCs. ADSCs at passage 3 and at $80-90 \%$ confluence were chosen as the seed cells. ADSCs $\left(1.0 \times 10^{7}\right)$ were seeded on the outer layer of the scaffold. The scaffolds were left in culture for 3 days for identification and surgical implantation. The samples were fixed with $2.5 \%$ glutaraldehyde and dehydrated with an ascending series of ethanol. Then, the samples were dried in a vacuum and sputter-coated with gold for SEM observation (Hitachi TM-1000, Japan).

Before seeding the ADSCs on the scaffold, the ADSCs were transfected by virus to emit red fluorescence according to the manufacturer's instructions (Hanbio, Shanghai, China). Briefly, $5 \times 10^{4}$ ADSCs were seeded in each well of a 24-well plate. The multiplicity of infection (MOI) was 30 . Puromycin $(8 \mu \mathrm{g} / \mathrm{ml})$ was used to select the infected ADSCs. ADSCs $\left(1.0 \times 10^{7} / \mathrm{ml}\right)$ were seeded on the outer layer of the scaffold $(2 \times 0.6 \mathrm{~cm})$. The cells were stained with DAPI solution and washed with PBS. The organization and morphology of the fluorescent ADSCs on the scaffold were observed by confocal laser scanning microscopy (CLSM, Carl Zeiss, Germany). The cell-seeded scaffold was immersed in optimal cutting temperature (OCT) medium. Sections of $8 \mu \mathrm{m}$ were generated with a freezing microtome (Thermo Scientific, USA), stained with a DAPI solution, and then observed by fluorescence microscopy (Nikon, Japan).

\section{Surgical procedure}

A total of 15 New Zealand white rabbits were chosen for surgery and divided into 3 groups: the $\mathrm{H}, \mathrm{N}$, and Normal groups. The rabbits in the $\mathrm{H}$ or $\mathrm{N}$ group received scaffolds integrated with its own isolated hypoxia- or normoxiapreconditioned ADSCs, respectively. The rabbits in the Normal groups only received inguinal adipose tissue isolation, its urethra is intact. In $\mathrm{H}$ or $\mathrm{N}$ groups, 3 rabbits were randomly chosen at 3 or 6 months after implantation and then humanely euthanized to harvest the urethra. In Normal groups, all 3 rabbits were humanely euthanized to harvest the urethra at 6 months for comparison.

The implantation of the cell-seeded scaffolds was performed by the same experienced surgeon. All the New Zealand white rabbits were intravenously injected with pentobarbital sodium for general anesthesia. Then, an 8Fr transurethral catheter was inserted into the urethra to support the urethra. After separating the rectum from the penis, a $2.0-\mathrm{cm}$ ventral midline longitudinal incision was made to expose the urethra. On the ventral side, a $2.0 \times 0.6 \mathrm{~cm}$ defect was made. The scaffolds integrated with hypoxia- or normoxia-preconditioned ADSCs were placed over the defect of the urethra. An interrupted suture was made to anastomose the edge of the scaffold and margin of the normal urethra with $6 / 0$ vicryl sutures (Ethicon, USA). The corpus spongiosum was closed in a routine fashion. The inserted catheter was immobilized for bladder drainage, and ampicillin $G(2 \mathrm{~g} /$ day $)$ was given intravenously as an anti-inflammatory measure 3 days postoperatively. Any poor states, such as dysuria, energielos, and gastrointestinal symptoms, were closely observed.

\section{Retrograde contrast urethrography}

Six months after the surgery, the rabbits receiving anterior urethroplasty were subjected to urethrography to determine the urethra caliber. Before urethrography, the rabbits were intravenously injected with pentobarbital sodium for general anesthesia. The rabbits were placed in the supine position. The catheter was inserted into the urethra and fixed with glans. The contrast medium, composed of Iobitridol (GE, China) mixed with normal saline at a 1:1 ratio, was injected into the catheter for the urethrogram. An X-ray machine (Philips, Netherlands) was used to capture the urethrography images.

\section{Morphological observation}

Three or 6 months after the surgery, the rabbits were euthanized by a lethal pentobarbital injection, and the reconstructed urethra was harvested. The acquired tissues were immersed in paraformaldehyde overnight and transferred to $30 \%$ sucrose in water for 3 days. The tissue was sectioned at a thickness of $8 \mu \mathrm{m}$ by a freezing microtome (Thermo Scientific, USA). Hematoxylineosin (H\&E) staining and immunofluorescence (IHC) staining were performed to assess the morphology, urothelial cell layer (ab961, Abcam), smooth muscle cells (ab7817, Abcam), and vessel tissue (ab778, Abcam). The nuclei were stained with DAPI. Six random microscopic fields were chosen in each section to evaluate the urothelium, smooth muscle, and blood vessels. The results were analyzed by Image-Pro Plus 6.0 software (Media Cybernetics, USA).

\section{Statistical analysis}

The data were analyzed by Statistics Package for Social Science (SPSS 24.0). $T$ test analysis and one-way and two-way ANOVA were applied for comparisons between groups. The final data are reported as the mean \pm standard deviation. $p<0.05$ represents statistical significance.

\section{Results}

Schematic of the fabrication of the scaffold, in vivo and in vitro experiments

Figure 1a is a schematic illustration of the fabrication of the porous bilayered nanofibrous scaffold. Figure $1 \mathrm{~b}$ 


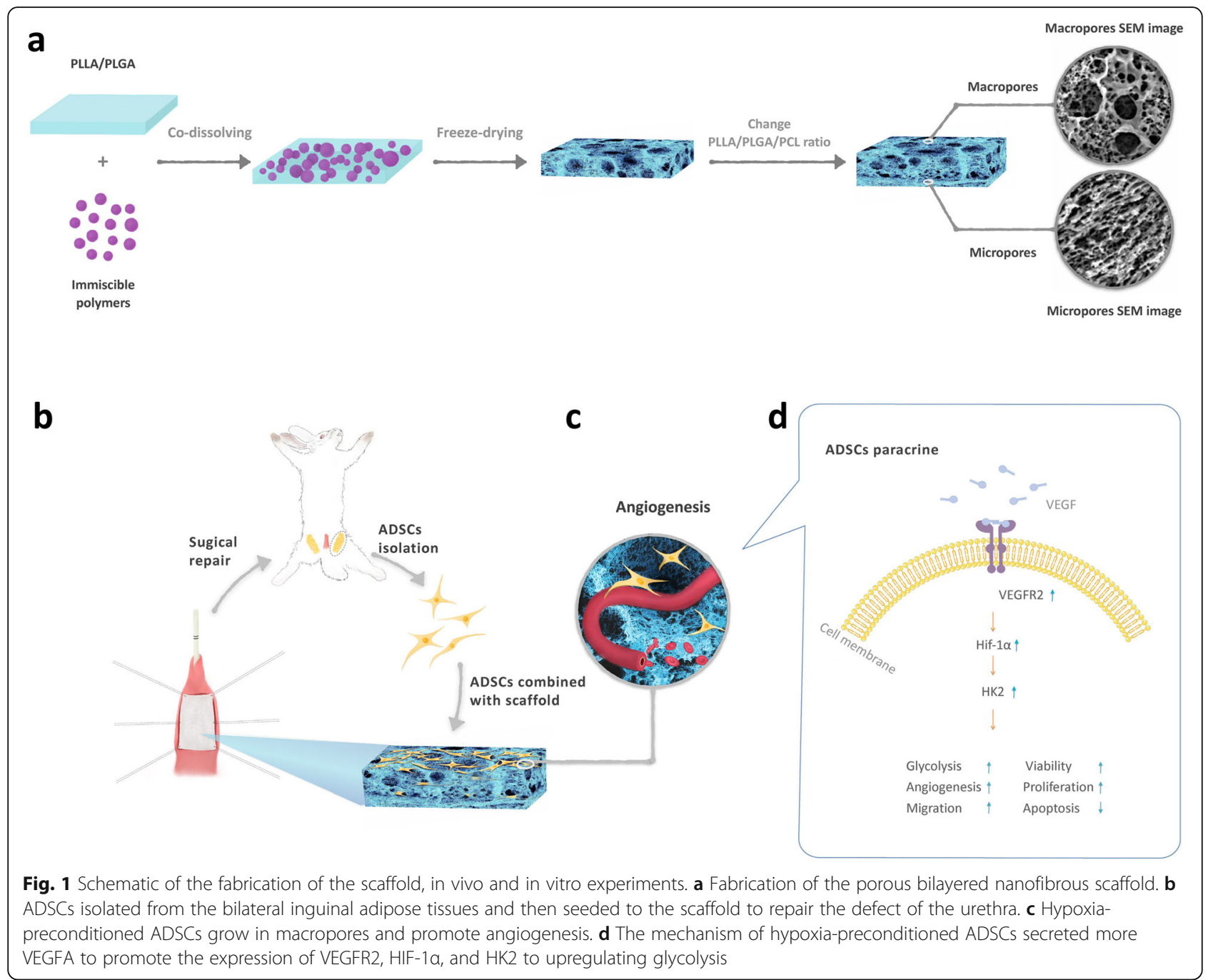

depicts that we isolate ADSCs from the bilateral inguinal adipose tissues and then seeded them to the scaffold to repair the defect of the urethra. Figure 1c illustrates hypoxia-preconditioned ADSCs grow in macropores and promote angiogenesis. Figure 1d illustrates the mechanism of hypoxia-preconditioned ADSCs secreted more VEGFA to promote the expression of VEGFR2, HIF- $1 \alpha$, and HK2 to upregulating glycolysis.

\section{ADSC morphology and multipotency analysis}

After isolation and culture, the ADSCs showed spindle-shaped, fibroblast-like morphology. ADSCs of passage $0-3$ were photographed and are shown in Fig. S1. Differentiation media were used to analyze the multipotency of the ADSCs. The adipogenic, chondrogenic, and osteogenic lineages are shown in Fig. S2.
Hypoxia-preconditioned ADSCs improve the proliferation and viability of HUVECs

To examine the possible effect of hypoxia-preconditioned ADSCs, CCK- 8 assays, colony formation assays, and flow cytometry were performed. Based on the outcome of the CCK8 assay, we found that the absorption of group $\mathrm{H}$ at 12,24 , and $48 \mathrm{~h}$ was significantly higher $(0.56 \pm 0.03$ vs $0.52 \pm 0.03$, $0.90 \pm 0.02$ vs $0.77 \pm 0.03,1.66 \pm 0.14$ vs $1.43 \pm 0.11$ absorption, respectively, all $p<0.05$ ) than that of group N (Fig. 2a). This indicates that hypoxia-preconditioned ADSCs could significantly improve the proliferation of HUVECs. The colony formation assays showed that the HUVECs treated with hypoxia-preconditioned ADSCs had improved colony-forming abilities and formed more colony units $(112.33 \pm 5.86$ vs $43.67 \pm 6.66, p<0.05)$ (Fig. 2b, c). Cell cycling largely reflects cell behavior and proliferation. Based on the cell cycle analysis (Fig. 2d, e), we observed more HUVECs at the $\mathrm{S}+$ $\mathrm{G} 2 / \mathrm{M}$ stage $(22.62 \pm 1.39$ vs $19.38 \pm 0.39 \%, p<0.05)$ 


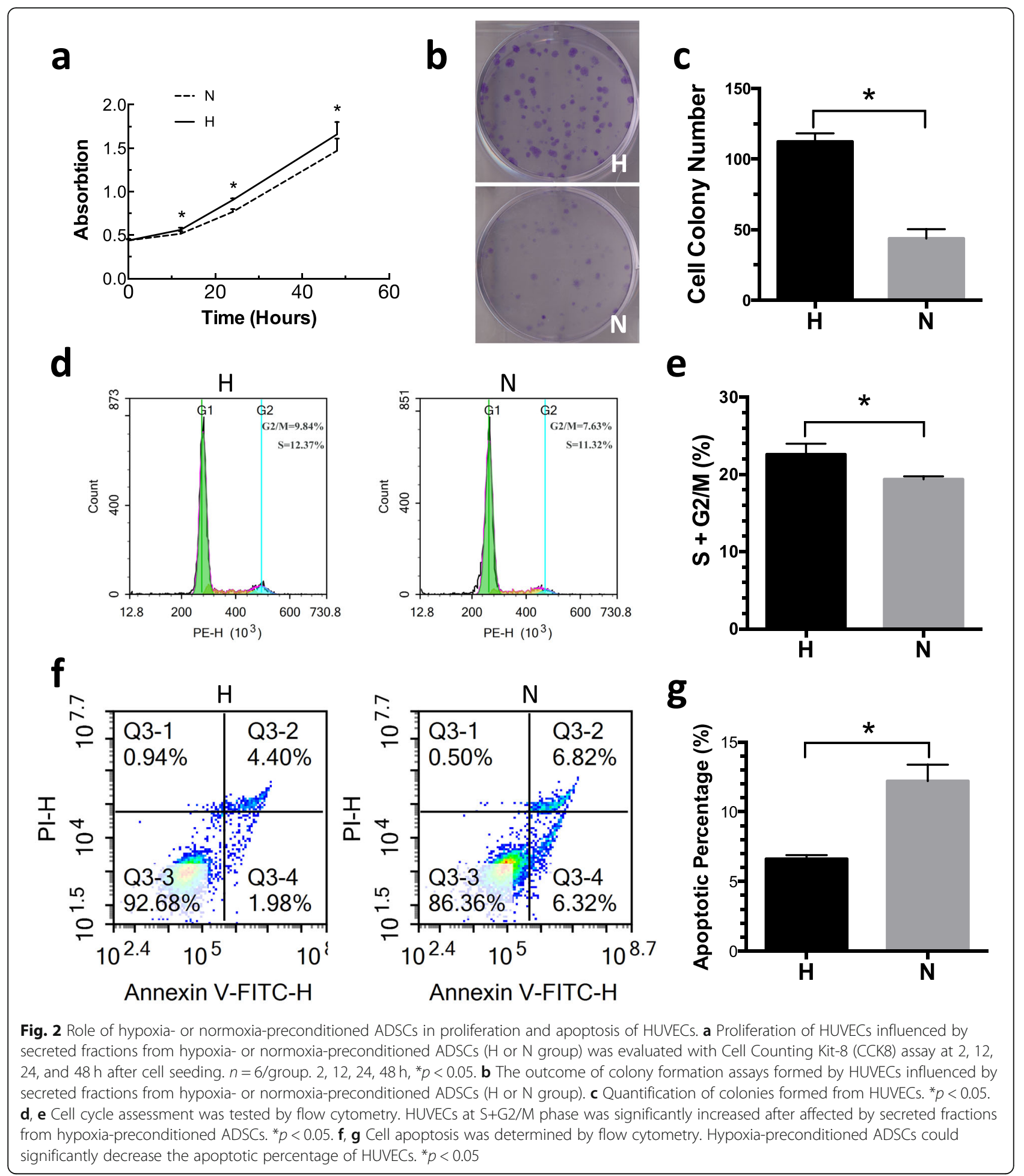

after treatment with hypoxia-preconditioned ADSCs. To investigate the anti-apoptotic role of hypoxiapreconditioned ADSCs, the HUVECs were stained with annexin $\mathrm{V}$ and measured by flow cytometry (Fig. 2f, g). The percentages of apoptotic HUVECs were significantly lower $(6.61 \pm 0.28$ vs $12.21 \pm 1.18 \%, p<0.05)$ after treatment with hypoxia-preconditioned ADSCs. These results showed that compared to normoxiapreconditioned ADSCs, hypoxia-preconditioned ADSCs could improve the proliferation and viability of HUVECs. 

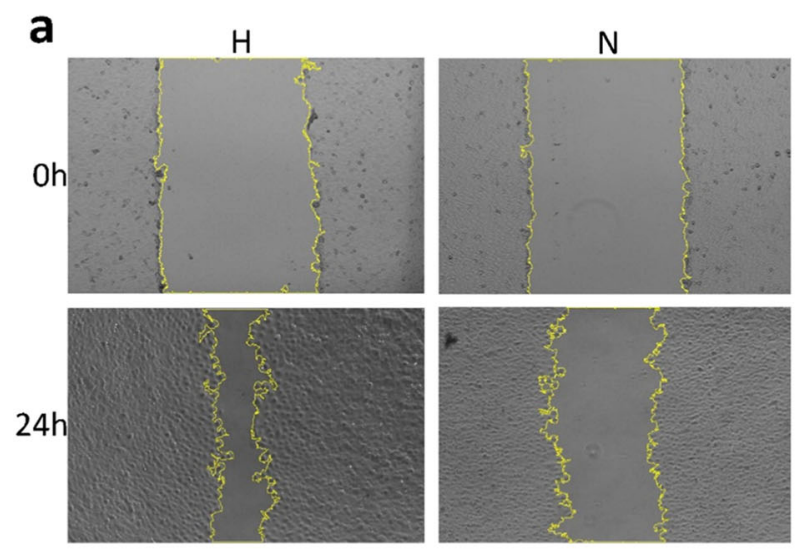

b
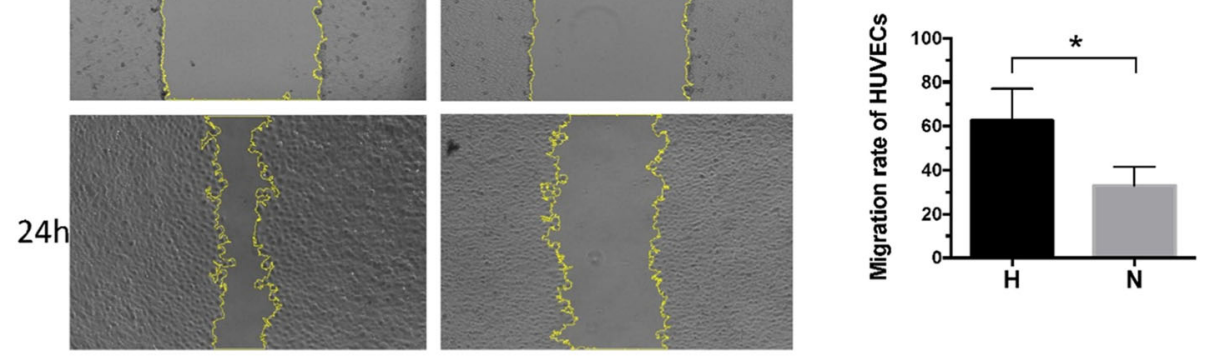

\section{C}

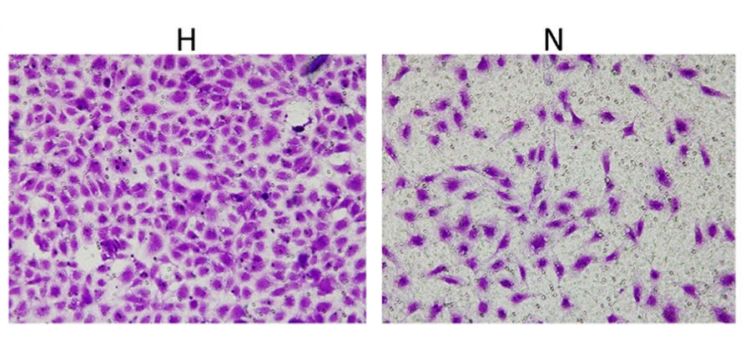

d

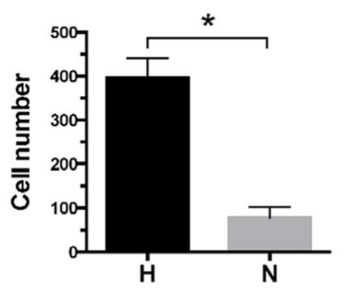

e
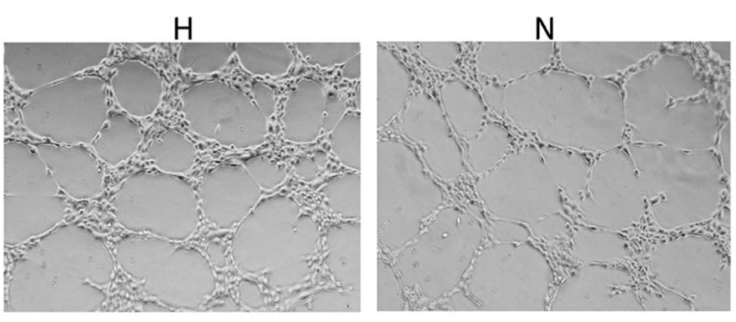

f
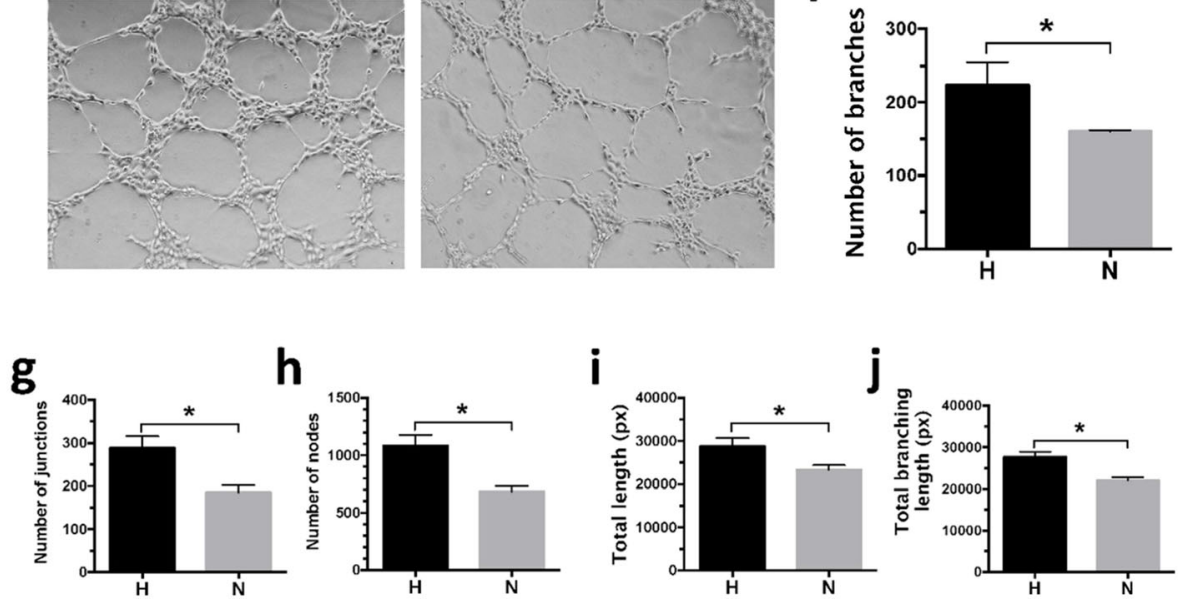

Fig. 3 Role of hypoxia- or normoxia-preconditioned ADSCs in migration and angiogenesis of HUVECs. a, b Representative photos of scratch on HUVECs at $0 \mathrm{~h}$ and $24 \mathrm{~h}$ after treated by secreted fractions from hypoxia- or normoxia-preconditioned ADSCs. The migration of HUVECs was significantly increased by secreted fractions from hypoxia-preconditioned ADSCs. ${ }^{*} p<0.05$. $\mathbf{c}$, d Representative photos of transwell migration assay of HUVECs after treated by secreted fractions from hypoxia- or normoxia-preconditioned ADSCs. Hypoxia-preconditioned ADSCs increased migrated HUVECs. ${ }^{*} p<0.05$. e In vitro tube formation of HUVECs at $10 \mathrm{~h}$ in different groups. $\mathbf{f}-\mathbf{j}$ The quantification of branches, junctions, nodes, total length, and total branching length was listed and measured by Image-Pro Plus 6.0 (IPP). ${ }^{*} p<0.05$

\section{Hypoxia-preconditioned ADSCs improve the migration of HUVECS}

To determine the effect of hypoxia-preconditioned ADSCs on HUVEC migration, wound healing assays and transwell migration assays were performed. Hypoxia- or normoxia-preconditioned ADSCs both facilitated wound closure at $24 \mathrm{~h}$. The percentage of the healed area at $24 \mathrm{~h}$ was significantly larger (62.57 \pm
14.57 vs $33.08 \pm 8.52 \%, p<0.05)$ after treatment with secreted fractions from hypoxia-preconditioned ADSCs (Fig. 3a, b). The migration-promoting effect of hypoxia-preconditioned ADSCs was further confirmed by a transwell migration assay. Figure $3 \mathrm{c}$ and $\mathrm{d}$ show that hypoxia-preconditioned ADSCs significantly increased the number of migrated HUVECs $(396.67 \pm 43.75$ vs $78.33 \pm 24.01, \quad p<0.05)$. These 


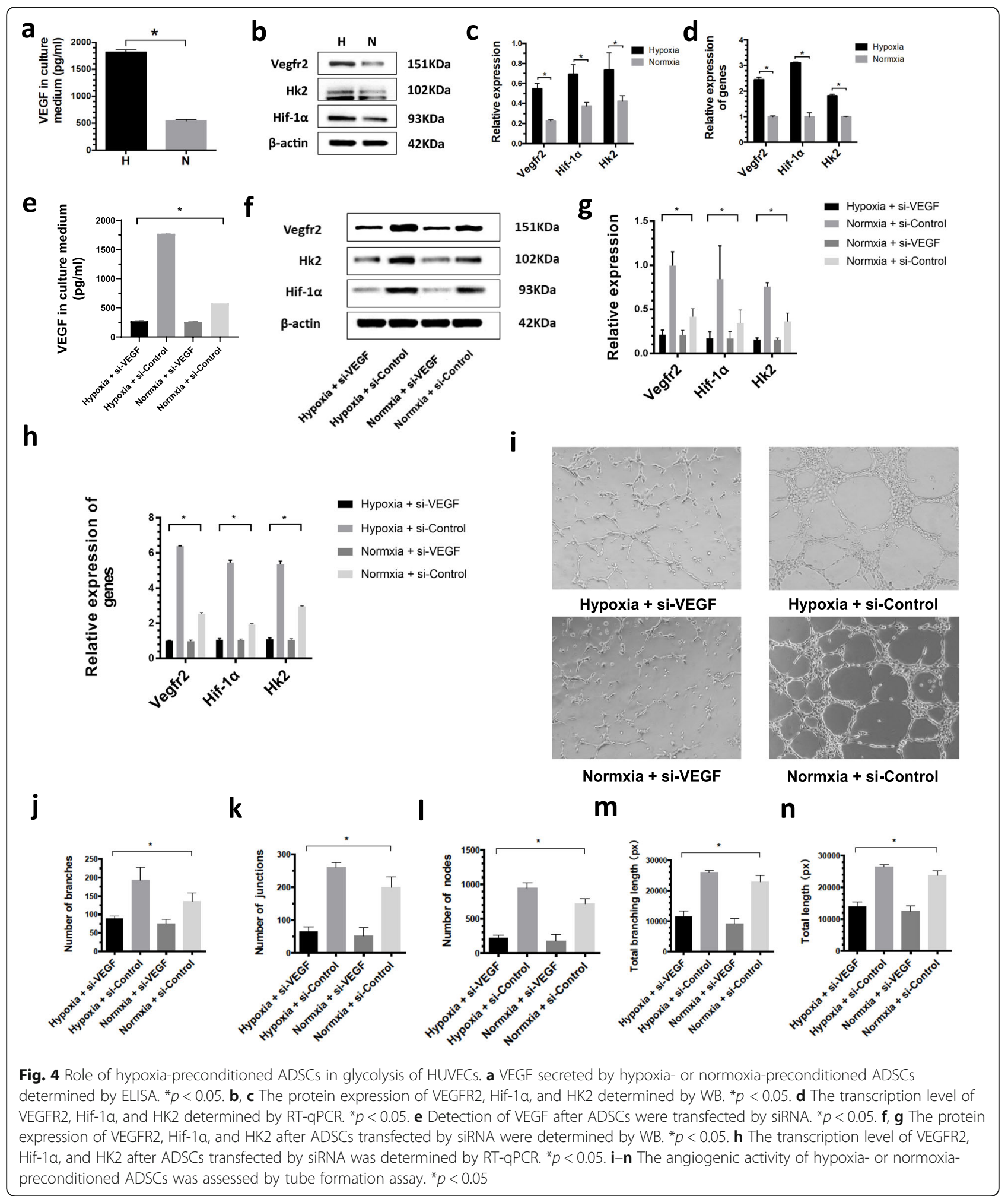


outcomes implied that hypoxia-preconditioned ADSCs could dramatically promote the migration capacity of HUVECs.

\section{Hypoxia-preconditioned ADSCs improve angiogenesis in vitro}

To evaluate the effect of hypoxia- or normoxiapreconditioned ADSCs on angiogenic capacity, tube formation assays were performed (Fig. 3e). The number of branches, junctions, and nodes; the total length; and the branching length were analyzed $(223.67 \pm 31.72$ vs $160.00 \pm 2.00,288 \pm 27.06$ vs $185 \pm$ $17.09, \quad 1083.33 \pm 94.48$ vs $686.00 \pm 46.70, \quad 28,798 \pm$ 1894.05 vs $23,352.67 \pm 1021.19 \quad \mathrm{px}, \quad 27,673.67 \pm$ 1267.75 vs $21,980.33 \pm 838.65 \mathrm{px}$, respectively, all $p<$ 0.05 , Fig. $3 f-j$ ). Our data showed that these features were significantly improved after hypoxiapreconditioned ADSC treatment compared with normoxia-preconditioned ADSC treatment. Therefore, compared to normoxia-preconditioned ADSCs, hypoxia-preconditioned ADSCs could facilitate angiogenesis in vitro.

\section{Hypoxia-preconditioned ADSCs upregulate VEGFA secretion}

To evaluate whether hypoxia-preconditioned ADSCs secrete more VEGF, an ELISA assay was performed. Figure $4 \mathrm{a}$ shows that hypoxia-preconditioned ADSCs secreted more VEGFA than normoxia-preconditioned ADSCs $(1814.92 \pm 43.17$ vs $541.05 \pm 25.49, p<0.05)$. There were no significant differences in the secreted HGF between hypoxia- and normoxia-preconditioned ADSCs (Fig. S3, $p>0.05$ ). The FGF content was too low and could not be measured.

\section{Hypoxia-preconditioned ADSCs facilitate the metabolic activity of HUVECs}

To examine the metabolic activity of HUVECs after treatment with secreted fractions from hypoxia- or normoxia-preconditioned ADSCs, the transcription and expression levels of VEGFR2, HIF- $1 \alpha$, and HK2 were examined. HIF- $1 \alpha$ and HK2 play vital roles in glycolysis [28]. The results showed that hypoxiapreconditioned ADSCs significantly upregulated the transcription of VEGFR2, HIF-1 $\alpha$, and HK2 $(2.45 \pm$ 0.09 vs $1.00 \pm 0.03,3.10 \pm 0.04$ vs $1.00 \pm 0.16,1.81 \pm$ 0.06 vs $1.00 \pm 0.02$, respectively, all $p<0.05$, Fig. $4 \mathrm{~d}$ ). Hypoxia-preconditioned ADSCs also significantly upregulated the protein expression of VEGFR2, HIF- $1 \alpha$, and HK2 compared to normoxia-preconditioned ADSCs $\quad(0.55 \pm 0.05$ vs $0.23 \pm 0.01, \quad 0.69 \pm 0.10 \quad$ vs $0.37 \pm 0.04, \quad 0.73 \pm 0.17$ vs $0.42 \pm 0.06$, all $p<0.05$, Fig. 4b, c). These results suggested that hypoxia- preconditioned ADSCs could improve the metabolic activity of HUVECs.

\section{Hypoxia-preconditioned ADSCs promote the metabolic activity and angiogenesis of HUVECs through VEGFA in vitro}

To determine what factors mediate the effects of ADSCs on promoting HUVEC metabolic activity and angiogenesis in vitro, we silenced the expressing of VEGFA. After silencing the expressing of VEGFA, we measured the content of VEGFA in the medium from hypoxia- or normoxia-preconditioned ADSCs. The results showed that the transfection of si-VEGF significantly suppressed VEGFA secretion into the medium $(268.42 \pm 10.99$ vs $1770.25 \pm 10.04$ vs $259.12 \pm 10.76$ vs $574.24 \pm 6.23$, Fig. 4e). HUVECs were treated with si-VEGF or siControl + hypoxia-preconditioned ADSCs and si-VEGF or si-Control + normoxia-preconditioned ADSCs, and the transcription and expression levels of VEGFR2, HIF$1 \alpha$, and HK2 were examined. The protein levels were significantly suppressed by si-VEGF + hypoxiapreconditioned ADSCs (VEGFR2, $0.21 \pm 0.05$ vs $1.00 \pm$ 0.16 vs $0.21 \pm 0.05$ vs $0.42 \pm 0.09$; HIF- $1 \alpha, 0.17 \pm 0.07$ vs $0.84 \pm 0.38$ vs $0.17 \pm 0.08$ vs $0.34 \pm 0.15$; HK2, $0.16 \pm 0.02$ vs $0.76 \pm 0.05$ vs $0.16 \pm 0.02$ vs $0.36 \pm 0.10$, Fig. $4 \mathrm{f}$, g). The mRNA results were identical (VEGFR2, $1.01 \pm 0.02$ vs $6.38 \pm 0.03$ vs $0.99 \pm 0.06$ vs $2.55 \pm 0.07$; HIF- $1 \alpha$, $1.07 \pm 0.06$ vs $5.46 \pm 0.14$ vs $1.06 \pm 0.05$ vs $1.93 \pm 0.05$; HK2, $1.09 \pm 0.09$ vs $5.37 \pm 0.18$ vs $1.06 \pm 0.07$ vs $2.97 \pm$ 0.04, Fig. 4h). Angiogenesis was also inhibited by siVEGF + hypoxia-preconditioned ADSCs (Fig. 4i). The branches, junctions, nodes, total branching length, and total length were significantly decreased after treatment with si-VEGF + hypoxia-preconditioned ADSCs (branches, $89.00 \pm 6.00$ vs $193.00 \pm 34.83$ vs $75.67 \pm 11.59$ vs $135.00 \pm 23.39$; junctions, $64.33 \pm 14.29$ vs $260.67 \pm$ 15.28 vs $49.67 \pm 28.02$ vs $200.67 \pm 30.37$; nodes, $219.33 \pm$ 41.79 vs $947.33 \pm 75.06$ vs $183.67 \pm 86.50$ vs $721.00 \pm$ 73.57; total branching length, $11,463.67 \pm 1885.01 \mathrm{px}$ vs $25,987.67 \pm 627.71$ px vs $9220.00 \pm 1564.82$ px vs 23 , $032.33 \pm 1933.45 \mathrm{px}$; total length, $13,948.67 \pm 1452.14 \mathrm{px}$ vs $26,428 \pm 755.52$ px vs $12,480.67 \pm 1764.79$ px vs 23 , $716.33 \pm 1507.00$ px, Fig. $4 j-n)$.

\section{Fabrication of the scaffold and combining cells with scaffold}

The gross morphology and SEM observations of the macroporous side, the microporous side, and the interface of the scaffold are shown in Fig. 5a-c. The macroporous side was densely covered with large enough pores to allow the infiltration of cells and interstitial fluid flow. The microporous side could serve as a barrier to resist urine and provide an ideal environment for the growth of epithelial cells [29, 


\section{a}

b
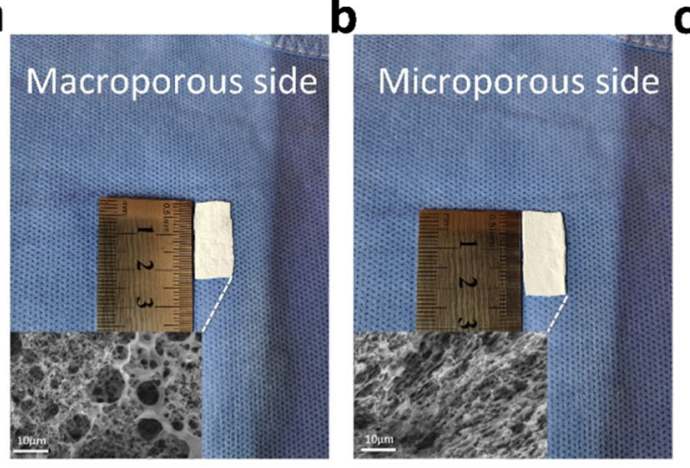

C

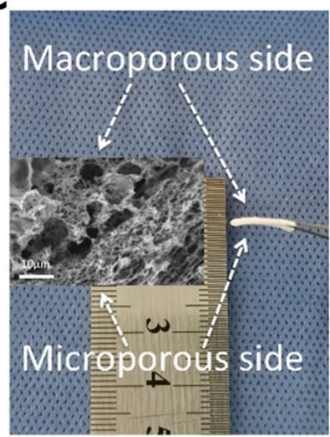

d
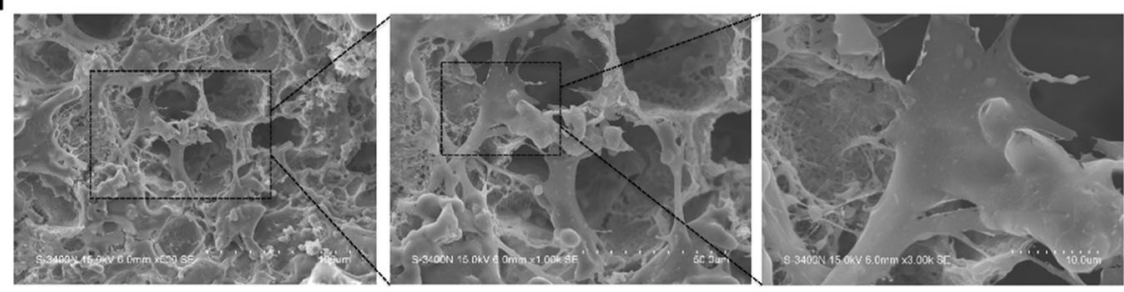

e
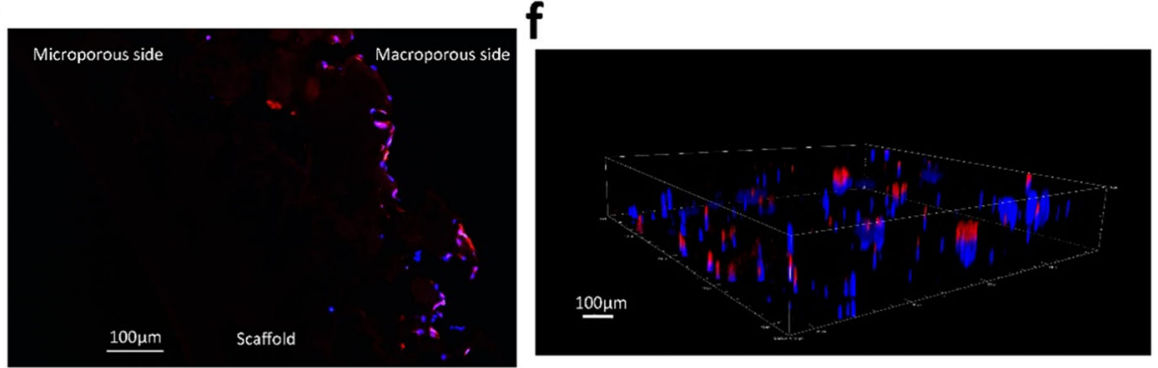

Fig. 5 The morphology of the scaffold and identification of ADSCs seeded on scaffold. a-c Macroporous, microporous, and cross-section sides of the scaffolds. The morphology of the scaffold was detected by SEM. Scale bar $=10 \mu \mathrm{m}$. $\mathbf{d}$ The HUVECs were attached with the pore of the scaffold and detected by SEM. Scale bar $=100 \mu \mathrm{m}$. e The immunofluorescence section of the scaffold was observed by a fluorescent microscope. Scale bar $=100 \mu \mathrm{m}$. $\mathbf{f}$ The organization and morphology of fluorescent ADSCs on the scaffold were observed by a confocal laser scanning microscope. Scale bar $=100 \mu \mathrm{m}$

30]. Figure 5d shows SEM images of ADSCs cultured on the scaffold. The ADSCs perfectly combined with the scaffold and permeated into the macropores, showing irregularly spread morphology with elongated pseudopodia. To further show that HUVECs successfully combined and grew into the scaffold, IHC and CLMS were performed. Figure $5 \mathrm{e}$ shows the transfected ADSCs emitting red fluorescence and located in the macropores of the scaffold. The ADSCs were stained with DAPI. Figure $5 f$ shows the threedimensional microstructure of the ADSCs and scaffolds. The $z$ axis of the CLSM image with a length of more than $75 \mu \mathrm{m}$ indicates that ADSCs were successfully located in the macropores of the scaffold. The above results showed that the scaffold successfully combined with the cells and that the pores were suitable for neotissue growth and infiltration.

\section{Hypoxia-preconditioned ADSCs lead to fewer complications and a larger urethral caliber} All rabbits survived the operation in which ADSCs combined with scaffolds were implanted. The surgical wounds healed 14 days postoperatively. Among the rabbits that received hypoxia-preconditioned ADSCs combined with scaffolds (group $\mathrm{H}$ ), four rabbits did not present with symptoms of dysuria, and only two rabbits presented mild dysuria that had no significant impact on survival. In group $\mathrm{N}$, after the removal of the urethral catheter, four of the rabbits presented symptoms of dysuria, such as thinner urine stream and distention of the bladder. One rabbit in group $\mathrm{N}$ 


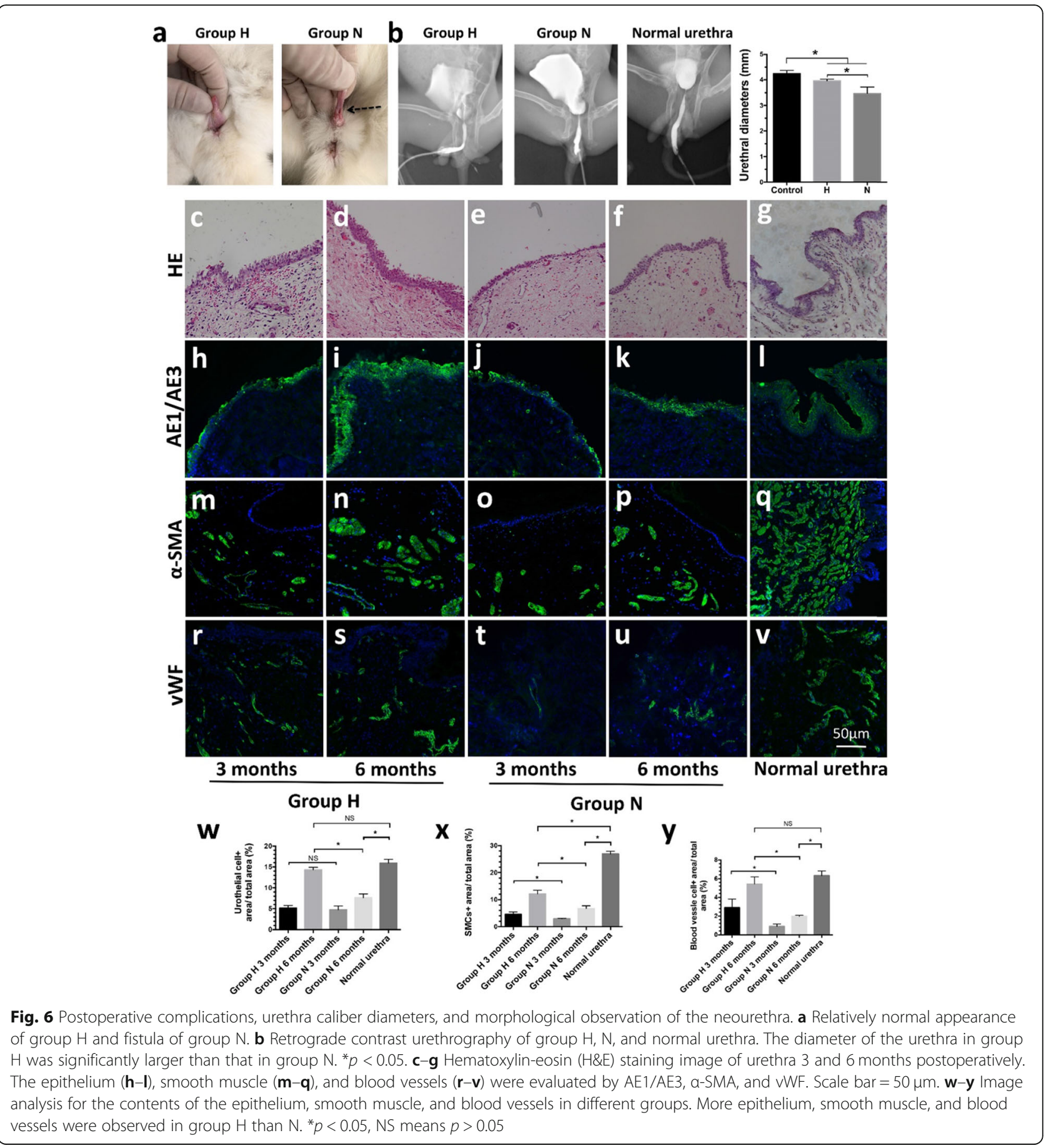

presented urethral fistulas, and the urine transmitted out of the fistula (Fig. 6a). All the rabbits survived until 3 or 6 months after implantation. Retrograde urethrography showed that the diameters of the urethras in group $\mathrm{H}$ were larger than those in group $\mathrm{N}$ $(p<0.05)$. However, the diameters of the normal urethras were wider than those in groups $\mathrm{H}$ and $\mathrm{N}$
$(4.24 \pm 0.13$ vs $3.96 \pm 0.07$ vs $3.47 \pm 0.24 \mathrm{~mm}, p<0.05$, Fig. 6b).

\section{Hypoxia-preconditioned ADSCs facilitate neotissue regeneration in vivo}

The regeneration of urothelial cells was confirmed by hematoxylin-eosin (H\&E) staining (Fig. 6c-g) and 
immunofluorescence (IHC) staining (Fig. 6h-l). Compared with those in group $\mathrm{N}$, in group $\mathrm{H}$, the urothelial cells were arranged in a more orderly manner and in thicker urothelial cell layers at 3 and 6 months $(p<0.05)$. The regenerated urothelial cells in group $\mathrm{H}$ at 6 months showed stratification comparable to that of the normal urothelial cell layers $(p>0.05)$. The regenerated epithelial cells in group $\mathrm{N}$ were loosely arranged and thinner than those in group $\mathrm{H}$ and in the normal urothelium (Fig. 6w, group $\mathrm{H} 3$ months vs group $\mathrm{H} 6$ months vs group $\mathrm{N} 3$ months vs group $\mathrm{N} 6$ months vs normal urethra, $4.87 \pm 1.56$ vs $16.16 \pm 3.30$ vs $4.66 \pm 1.33$ vs $8.37 \pm 1.06$ vs $17.39 \pm 2.94 \%$, respectively). The smooth muscle cells (SMCs) were identified by the emission of bright green fluorescence (Fig. $6 \mathrm{~m}-\mathrm{q}$ ) and HE staining (Fig. $6 \mathrm{c}-\mathrm{g}$ ). The SMC density of group $\mathrm{H}$ at 6 months was significantly increased compared with that of group $\mathrm{N}$ at 3 months $(p<0.05)$, and it was also significantly higher than that of group $\mathrm{N}$ at 3 or 6 months $(p<0.05)$. However, the SMC content of group $\mathrm{H}$ at 6 months was still significantly lower than that of the normal urethra $(p<0.05)$ (Fig. 6x, group H 3 months vs group $\mathrm{H} 6$ months vs group $\mathrm{N} 3$ months vs group $\mathrm{N} 6$ months vs normal urethra, $6.68 \pm 2.16$ vs $15.00 \pm 2.45$ vs $3.71 \pm 0.76$ vs $7.08 \pm 1.77$ vs $22.60 \pm 2.74 \%$, respectively). The regenerated vessel tissue was stained and emitted bright green fluorescence (Fig. $6 \mathrm{r}-\mathrm{v}$ ). At 3 months, there was significantly more regenerated blood vessel tissue in group $\mathrm{H}$ than in group $\mathrm{N}(p<0.05)$, showing the role of hypoxiapreconditioned ADSCs in angiogenesis. The regenerated blood vessel tissue of group $\mathrm{H}$ at 6 months was well organized, comparable to the normal urethra $(p>0.05)$ and significantly more well organized than that of group $\mathrm{N}(p<0.05)$ (Fig. 6y, group $\mathrm{H} 3$ months vs group $\mathrm{H} 6$ months vs group $\mathrm{N} 3$ months vs group $\mathrm{N} 6$ months vs normal urethra, $5.15 \pm 1.11$ vs $7.05 \pm 0.62$ vs $3.40 \pm 0.59$ vs $5.04 \pm 0.66$ vs $7.34 \pm 1.19 \%$, respectively).

\section{Discussion}

Our study evaluated the use of hypoxia- vs. normoxiapreconditioned ADSCs combined with a novel porous scaffold for anterior urethroplasty. The key finding is that hypoxia-preconditioned ADSCs facilitate the viability, migration, and angiogenesis of blood endothelial cells (ECs) for tissue regeneration, probably via increased glycolysis.

The identification of the appropriate hypoxic culture conditions is of great significance. Determining the ideal oxygen tension is the key to exploring the optimal culture conditions. ADSCs have been reported to reside in a lower (i.e., $1-5 \% \mathrm{O}_{2}$ ) oxygen tension than that typically used in ambient cell culture (20-21\%) [5]. Due to the lack of vascularization, in the early period of tissue regeneration, the oxygen tension may be lower than $4 \%$
[31]. Therefore, we used $1 \% \mathrm{O}_{2}$ oxygen tension to simulate the oxygen conditions after cell-scaffold transplantation. Zhang et al. found that after hypoxia preconditioning, ADSCs secreted more angiogenic factors. Angiogenesis and histological injury were both significantly improved, and renal function was protected [32]. Valorani et al. revealed that compared to normoxic conditions, hypoxic conditions could enhance the migration and viability of ADSCs [33]. Stubbs et al. reported that after preconditioning with simulated hypoxia and ischemia conditions, ADSCs exhibited increased viability and reduced cell injury. The media of hypoxiapreconditioned ADSCs could enhance endothelial cell survival and angiogenesis capacity in vitro [34]. Our in vitro CCK-8, colony formation and flow cytometry data revealed that hypoxia-preconditioned ADSCs exhibited better function in promoting cell proliferation. These results are consistent with previous reports [33]. Subsequent tests showed that compared to normoxiapreconditioned ADSCs, hypoxia-preconditioned ADSCs could improve the migration of HUVECs. This finding is identical to previous results showing that conditioned medium derived from hypoxia-preconditioned ADSCs could enhance the migration of primary gastric mucosal epithelial cells (GECs) in vitro [35]. In addition, hypoxiapreconditioned ADSCs lead to greater angiogenic effects because they secrete more VEGFA and promote endothelial tube formation. This observation conforms to our results revealing that the increased paracrine production of VEGF-A by hypoxia-preconditioned ADSCs leads to a significantly diminished angiogenic response [17].

In our study, VEGFA and VEGFR2 were chosen as the main mediators of the effect of ADSCs on HUVECs. VEGFA is one of the most important vascularizationrelated factors and plays a vital role in vascularization and tissue engineering [23]. It has also been reported that VEGFA can increase glycolysis and ensure physiological metabolism $[20,36]$. There is consensus that VEGFR-2 is the main receptor of VEGFA that plays an angiogenic role via tyrosine phosphorylation [31]. Therefore, we believe that in the interaction between ADSCs and HUVECs, VEGFA and VEGFR2 may represent two targeted molecules. The HIF-1 pathway plays a leading role in angiogenesis, glycolysis, and the hypoxic response. The stabilization of HIF- $1 \alpha$, the master glycolytic regulator, can upregulate glycolysis to promote cell viability and proliferation [37]. HIF-1 $\alpha$ can combine with HIF-1 $\beta$ to bind to the hypoxia response element (HRE) in the cellular nucleus to regulate or reprogram genes related to glycolysis, such as HK2, which is the first ratelimiting enzyme in glycolysis [28]. As shown in our results, the cytokines secreted by hypoxia-preconditioned ADSCs could stimulate the HIF- $1 \alpha-\mathrm{HK} 2$ axis. The WB and RT-PCR results showed that HIF- $1 \alpha$ and HK2 were 
both significantly upregulated. The angiogenesis function was enhanced, as shown by the tube formation test. After silencing VEGF expression in ADSCs, there was a marked decrease in the VEGF content. VEGFR-2, the key angiogenic receptor [38], was also downregulated. The WB and RT-PCR results showed that HIF- $1 \alpha$ and HK2 were both significantly downregulated. The tube formation test showed that the angiogenic function of HUVECs was suppressed.

The phenomenon of the reliance of vessel endothelial cells on glycolysis is counterintuitive because endothelial cells are in close contact with oxygen in the blood, and one unit of glucose can produce 20 -fold more ATP by the TCA cycle than by glycolysis [39]. In fact, less than $1 \%$ glucose in ECs enters the TCA cycle, and oxidative phosphorylation generates only $10 \%$ of all the ATP in ECs [22]. This phenomenon could be explained by various reasons. First, the levels of oxygen and glucose are both low in avascular tissues, but glucose diffuses further than oxygen. When endothelial cells sprout into avascular tissues, they can rely on glucose rather than oxygen to form vessels, as long as glucose is not limiting [40, 41]. Second, endothelial cells consume little oxygen by glycolysis, which can save more oxygen for perivascular cells. Third, compared to the tricarboxylic acid (TCA) cycle of oxidative metabolism, glycolysis can generate ATP more rapidly to supply energy during sprouting. Tip cells extend lamellipodia and filopodia to migrate. The formation of these motile structures relies on the remodeling of the actin cytoskeleton, which is a process that requires the rapid production of high amounts of ATP. Fourth, endothelial cells can reduce the harm of oxidation by minimizing the level of oxidative metabolism. Finally, the substrate for the macromolecules generated by glycolysis is essential for cell duplication and division [22].

Urethral defects or strictures affect nearly $1 \%$ of the male population and severely disrupt physical and mental conditions of these patients [42]. In the last two decades, the best tissue for use in urethral repair is the buccal mucosa [43]. However, obtaining the buccal mucosa may cause donor site morbidity. In these cases, tissue engineering techniques represent an alternative material for urethroplasty. These techniques can avoid the complications related to graft harvesting at the buccal mucosa site and provide a convenient and feasible substitution for reconstruction [43]. Cells combined with scaffolds are innovative methods to repair and regenerate the urethra. Liu et al. isolated urine-derived stem cells and seeded them onto the small intestinal submucosa (SIS) to repair the ventral side of the penile urethra in a rabbit model and achieved a satisfactory outcome [44]. Li et al. harvested and expanded rabbit bone mesenchymal stem cells (BMSCs) and smooth muscle cells (SMCs) and seeded them onto a bladder acellular matrix (BAM). After 2 weeks of implantation in the rabbit omentum, the graft was transplanted. Compared to cells combined with BAM, an acellular BAM showed a significantly higher rate of urethral strictures [45]. Filippo et al. compared collagen matrices with or without endothelial cells and SMCs. It was revealed that collagen matrices without cells lead to poor tissue development and stricture formation [46]. In our study, scaffolds combined with hypoxia-conditioned ADSCs accelerated the growth of vascular, muscle, and epithelial cells, making the structure closer to normal tissue. These scaffolds gain a better therapeutic effect with a larger diameter of the urethra lumen.

The scaffold serves as a temporary ECM for the proliferation and attachment of cells and plays a critical role in tissue regeneration [47]. Poly lactic-co-glycolic acid (PLGA) has good biodegradability and biocompatibility and is widely used in tissue engineering. PLGA degrades more rapidly and can be miscible with PLLA/PCL to accelerate the degradation of scaffolds [48]. A highly porous scaffold can provide the best environment for oxygen exchange, nutrient transport, and cell infiltration and then promote the growth of neotissues [49]. However, organs with lumens, such as the urethra and blood vessels, consist of layered cells and need heterogeneous porous structures for cell growth and tissue engineering applications [25]. The heterogeneous macroporous, nanofibrous side of the scaffold facilitates the infiltration of SMCs and vessel ECs, and the heterogeneous microporous luminal surface facilitates the growth of surrounding urethral epithelial cells [25]. The seeded ADSCs accelerate angiogenesis to supply oxygen and nutrients to urethral epithelial cells. The newly formed epithelium and the microporous luminal surface can protect the seeded cells and neotissues from urine, which could lead to urethral shrinkage, stricture, and obstruction. Therefore, the outer layer and inner layer complement each other and promote each other's function. The interconnected heterogeneous pores $(>120 \mu \mathrm{m})$ closely mimic the pores of the ECM, and the average fiber diameter is similar to that of natural ECM fibers. In addition, it has been reported that the therapeutic ability of stem cells could be enhanced by grafts that support cell-cell interactions [6]. Therefore, the cells seeded on the macroporous side of our scaffold may enhance the paracrine ability due to increased cell-cell interactions.

Our study has several limitations. First, due to the limitations of the current technology, it is difficult to measure the exact oxygen concentration during the tissue engineering-mediated repair and regeneration of new tissue. Second, our animal experiments were conducted in normal animals, which cannot completely imitate the urethral conditions observed in the clinic. In the next phase, a new urethral model with a fibrotic urethral bed needs to be developed. Finally, the sexual function of the 
rabbits also needs to be tested, so the technology and equipment for detecting sexual function in rabbits need to be renewed.

\section{Conclusions}

In summary, our study showed that hypoxiapreconditioned ADSCs combined with the newly fabricated PLLA/PCL/PLGA scaffold may offer innovative strategies for urethral reconstruction. In vitro, hypoxiapreconditioned ADSCs could secrete more VEGFA to promote the viability, proliferation, migration, and angiogenesis of blood ECs by increasing glycolysis. In vivo, the implantation of hypoxia-preconditioned ADSCs combined with scaffolds achieved better morphological preservation and revascularization. Due to the convenience of hypoxia treatment and the lack of genetic modification, hypoxia-preconditioned ADSCs combined with novel scaffold may be a promising alternative treatment for patients suffering from urethral defects or strictures in the clinic.

\section{Supplementary Information}

The online version contains supplementary material available at https://doi. org/10.1186/s13287-020-02052-4.

Additional file 1. Supplementary figures and table

\begin{abstract}
Abbreviations
ADSCs: Adipose-derived stem cells; HUVECs: Human umbilical vein endothelial cells; ELISA: Enzyme-linked immunosorbent assay; VEGFA: Vascular endothelial growth factor-A; ATP: Adenosine triphosphate; ECM: Extracellular matrix; H\&E: Hematoxylin and eosin; a-MEM: a-Modified Eagle's medium; FBS: Fetal bovine serum; CCK-8: Cell Counting Kit-8; FGF: Fibroblast growth factor; HGF: Hepatocyte growth factor; WB: Western blotting; RT-qPCR: Quantitative real-time polymerase chain reaction; HIF1a: Hypoxia-inducible factor-1a; HK2: Hexokinase 2; siRNA: Small interfering RNA; TIPS: Thermally induced phase separation; SEM: Scanning electron microscopy; IHC: Immunohistochemistry; CLSM: Confocal laser scanning microscopy; SPSS: Statistics Package for Social Science; IPP: Image-Pro Plus; SMCs: Smooth muscle cells; GECs: Gastric mucosal epithelial cells; HRE: Hypoxia response element; TCA: Tricarboxylic acid; SIS: Small intestinal submucosa; BMSCs: Bone mesenchymal stem cells; BAM: Bladder acellular matrix; PLGA: Poly lactic-co-glycolic acid; PLLA: Poly I-lactic acid; PCL: Poly caprolactone; ECs: Endothelial cells
\end{abstract}

\section{Acknowledgements}

We sincerely thank Sheng-qing Wang for helping us with the schematic illustration.

\section{Authors' contributions}

XW and MKX performed the research; HX participated in data processing and statistical analyses; ZWW and HJY provided experimental technical support; XW and MKX wrote the manuscript; DCZ and ZW conceived the research project. The authors read and approved the final manuscript.

\section{Funding}

This study was supported by the National Natural Science Foundation of China (81700582) and Cross-disciplinary Research Fund of Shanghai Ninth People's Hospital, Shanghai Jiao Tong University School of Medicine (JYJC201912).

\section{Availability of data and materials}

The datasets used and/or analyzed during the current study are available from the corresponding author on reasonable request.

\section{Ethics approval and consent to participate}

All animal procedures were approved by the Animal Ethics Committee of Shanghai University of Traditional Chinese Medicine (Reference no: P2SHUTCM200424005) and carried out in accordance with the guidelines for the National Institutes of Health Guide for the Care and Use of Laboratory Animals.

\section{Consent for publication}

Not applicable.

\section{Competing interests}

The authors declare that they have no known competing financial interests or personal relationships that could have appeared to influence the work reported in this paper.

Received: 30 August 2020 Accepted: 26 November 2020 Published online: 11 December 2020

\section{References}

1. Lv X, Li Z, Chen S, Xie M, Huang J, Peng X, Yang R, Wang H, Xu Y, Feng C. Structural and functional evaluation of oxygenating keratin/silk fibroin scaffold and initial assessment of their potential for urethral tissue engineering. Biomaterials. 2016;84:99-110.

2. Lumen N, Oosterlinck W, Hoebeke P. Urethral reconstruction using buccal mucosa or penile skin grafts: systematic review and meta-analysis. Urol Int. 2012;89:387-94.

3. Orabi H, AbouShwareb T, Zhang Y, Yoo JJ, Atala A. Cell-seeded tubularized scaffolds for reconstruction of long urethral defects: a preclinical study. Eur Urol. 2013;63:531-8.

4. Bhargava S, Patterson JM, Inman RD, MacNeil S, Chapple CR. Tissue-engineered buccal mucosa urethroplasty-clinical outcomes. Eur Urol. 2008:53:1263-9.

5. Choi JR, Yong KW, Wan Safwani WKZ. Effect of hypoxia on human adiposederived mesenchymal stem cells and its potential clinical applications. Cell Mol Life Sci. 2017;74:2587-600.

6. Qazi TH, Mooney DJ, Duda GN, Geissler S. Biomaterials that promote cellcell interactions enhance the paracrine function of MSCs. Biomaterials. 2017; 140:103-14.

7. Baraniak PR, McDevitt TC. Stem cell paracrine actions and tissue regeneration. Regen Med. 2010;5:121-43.

8. Caplan Al, Correa D. The MSC: an injury drugstore. Cell Stem Cell. 2011;9:11-5.

9. Beegle J, Lakatos K, Kalomoiris S, Stewart H, Isseroff RR, Nolta JA, Fierro FA. Hypoxic preconditioning of mesenchymal stromal cells induces metabolic changes, enhances survival, and promotes cell retention in vivo. Stem cells (Dayton). 2015;33:1818-28.

10. Hu X, Xu Y, Zhong Z, Wu Y, Zhao J, Wang Y, Cheng H, Kong M, Zhang F, Chen Q, Sun J, Li Q, Jin J, Li Q, Chen L, Wang C, Zhan H, Fan Y, Yang Q, Yu L, Wu R, Liang J, Zhu J, Wang Y, Jin Y, Lin Y, Yang F, Jia L, Zhu W, Chen J, Yu H, Zhang J, Wang J. A large-scale investigation of hypoxia-preconditioned allogeneic mesenchymal stem cells for myocardial repair in nonhuman primates: paracrine activity without remuscularization. Circ Res. 2016;118:970-83.

11. Kang S, Kim SM, Sung JH. Cellular and molecular stimulation of adiposederived stem cells under hypoxia. Cell Biol Int. 2014;38:553-62.

12. Przybyt E, Krenning G, Brinker MG, Harmsen MC. Adipose stromal cells primed with hypoxia and inflammation enhance cardiomyocyte proliferation rate in vitro through STAT3 and Erk1/2. J Transl Med. 2013;11:39.

13. Skiles ML, Sahai S, Rucker L, Blanchette JO. Use of culture geometry to control hypoxia-induced vascular endothelial growth factor secretion from adipose-derived stem cells: optimizing a cell-based approach to drive vascular growth. Tissue Eng A. 2013;19:2330-8.

14. Zhu H, Sun A, Zou Y, Ge J. Inducible metabolic adaptation promotes mesenchymal stem cell therapy for ischemia: a hypoxia-induced and glycogen-based energy prestorage strategy. Arterioscler Thromb Vasc Biol. 2014;34:870-6.

15. Yeh LC, Chen SP, Liao FH, Wu TH, Huang YT, Lin SY. The bioactive core and corona synergism of quantized gold enables slowed inflammation and increased tissue regeneration in wound hypoxia. Int J Mol Sci. 2020;21:1699.

16. Rey S, Luo W, Shimoda LA, Semenza GL. Metabolic reprogramming by HIF-1 promotes the survival of bone marrow-derived angiogenic cells in ischemic tissue. Blood. 2011;117:4988-98.

17. Hsiao ST, Lokmic Z, Peshavariya H, Abberton KM, Dusting GJ, Lim SY, Dilley RJ. Hypoxic conditioning enhances the angiogenic paracrine activity of human adipose-derived stem cells. Stem Cells Dev. 2013;22:1614-23. 
18. Han Y, Ren J, Bai Y, Pei X, Han Y. Exosomes from hypoxia-treated human adipose-derived mesenchymal stem cells enhance angiogenesis through VEGFNEGF-R. Int J Biochem Cell Biol. 2019;109:59-68.

19. Zhang $Y$, Hao Z, Wang P, Xia Y, Wu J, Xia D, Fang S, Xu S. Exosomes from human umbilical cord mesenchymal stem cells enhance fracture healing through HIF-1a-mediated promotion of angiogenesis in a rat model of stabilized fracture. Cell Prolif. 2019;52:e12570.

20. De Bock K, Georgiadou M, Carmeliet P. Role of endothelial cell metabolism in vessel sprouting. Cell Metab. 2013;18:634-47.

21. Li Y, Sun R, Zou J, Ying Y, Luo Z. Dual roles of the AMP-activated protein kinase pathway in angiogenesis. Cells. 2019;8:752.

22. K. De Bock, M. Georgiadou, S. Schoors, A. Kuchnio, B.W. Wong, A.R. Cantelmo, A. Quaegebeur, B. Ghesquiere, S. Cauwenberghs, G. Eelen, L.K. Phng, I. Betz, B. Tembuyser, K. Brepoels, J. Welti, I. Geudens, I. Segura, B. Cruys, F. Bifari, I. Decimo, R. Blanco, S. Wyns, J. Vangindertael, S. Rocha, R.T. Collins, S. Munck, D. Daelemans, H. Imamura, R. Devlieger, M. Rider, P.P. Van Veldhoven, F. Schuit, R. Bartrons, J. Hofkens, P. Fraisl, S. Telang, R.J. Deberardinis, L. Schoonjans, S. Vinckier, J. Chesney, H. Gerhardt, M. Dewerchin, P. Carmeliet, Role of PFKFB3-driven glycolysis in vessel sprouting. Cell. 2013; 154: 651-63.

23. An Y, Liu WJ, Xue P, Ma Y, Zhang LQ, Zhu B, Qi M, Li LY, Zhang YJ, Wang QT, Jin Y. Autophagy promotes MSC-mediated vascularization in cutaneous wound healing via regulation of VEGF secretion. Cell Death Dis. 2018;9:58.

24. Wan X, Zheng D, Yao H, Fu S, Wei Z, Wang Z, Xie M. An extracellular matrixmimicking, bilayered, heterogeneous, porous, nanofibrous scaffold for anterior urethroplasty in a rabbit model. Biomed Mater. 2020;15(6). https:// doi.org/10.1088/1748-605X/ab9fd0.

25. Wang W, Nie W, Zhou X, Feng W, Chen L, Zhang Q, You Z, Shi Q, Peng C, He C. Fabrication of heterogeneous porous bilayered nanofibrous vascular grafts by two-step phase separation technique. Acta Biomater. 2018;79:168-81.

26. Wang W, Nie W, Liu D, Du H, Zhou X, Chen L, Wang H, Mo X, Li L, He C. Macroporous nanofibrous vascular scaffold with improved biodegradability and smooth muscle cells infiltration prepared by dual phase separation technique. Int J Nanomedicine. 2018;13:7003-18.

27. Chen X, Yan L, Guo Z, Chen Z, Chen Y, Li M, Huang C, Zhang X, Chen L. Adipose-derived mesenchymal stem cells promote the survival of fat grafts via crosstalk between the Nrf2 and TLR4 pathways. Cell Death Dis. 2016;7:e2369.

28. Semenza GL. HIF-1 mediates metabolic responses to intratumoral hypoxia and oncogenic mutations. J Clin Invest. 2013;123:3664-71.

29. Eberli D, Freitas Filho L, Atala A, Yoo JJ. Composite scaffolds for the engineering of hollow organs and tissues. Methods (San Diego). 2009;47:109-15.

30. Horst M, Madduri S, Milleret V, Sulser T, Gobet R, Eberli D. A bilayered hybrid microfibrous PLGA--acellular matrix scaffold for hollow organ tissue engineering. Biomaterials. 2013;34:1537-45.

31. Kang K, Chuai JB, Xie BD, Li JZ, Qu H, Wu H, Fang SH, Cui JJ, Xiu LL, Han JC, Cao TH, Leng XP, Tian H, Li RK, Jiang SL. Mesenchymal stromal cells from patients with cyanotic congenital heart disease are optimal candidate for cardiac tissue engineering. Biomaterials. 2020;230:119574.

32. Zhang W, Liu L, Huo Y, Yang Y, Wang Y. Hypoxia-pretreated human MSCS attenuate acute kidney injury through enhanced angiogenic and antioxidative capacities. Biomed Res Int. 2014;2014:462472.

33. Valorani MG, Montelatici E, Germani A, Biddle A, D'Alessandro D, Strollo R, Patrizi MP, Lazzari L, Nye E, Otto WR, Pozzilli P, Alison MR. Pre-culturing human adipose tissue mesenchymal stem cells under hypoxia increases their adipogenic and osteogenic differentiation potentials. Cell Prolif. 2012;45:225-38.

34. Stubbs SL, Hsiao ST, Peshavariya HM, Lim SY, Dusting GJ, Dilley RJ. Hypoxic preconditioning enhances survival of human adipose-derived stem cells and conditions endothelial cells in vitro. Stem Cells Dev. 2012;21:1887-96.

35. Xia X, Chiu PWY, Lam PK, Chin WC, Ng EKW, Lau JYW. Secretome from hypoxia-conditioned adipose-derived mesenchymal stem cells promotes the healing of gastric mucosal injury in a rodent model. Biochim Biophys Acta Mol Basis Dis. 2018;1864:178-88.

36. Domigan CK, Warren CM, Antanesian V, Happel K, Ziyad S, Lee S, Krall A, Duan L, Torres-Collado AX, Castellani LW, Elashoff D, Christofk HR, van der Bliek AM, Potente M, Iruela-Arispe ML. Autocrine VEGF maintains endothelial survival through regulation of metabolism and autophagy. J Cell Sci. 2015; 128:2236-48.

37. Denko NC. Hypoxia, HIF1 and glucose metabolism in the solid tumour. Nat Rev Cancer. 2008;8:705-13.

38. Simons M, Gordon E, Claesson-Welsh L. Mechanisms and regulation of endothelial VEGF receptor signalling. Nat Rev Mol Cell Biol. 2016;17:611-25.
39. Vander Heiden MG, Cantley LC, Thompson CB. Understanding the Warburg effect: the metabolic requirements of cell proliferation. Science (New York). 2009;324:1029-33

40. Buchwald P. A local glucose-and oxygen concentration-based insulin secretion model for pancreatic islets. Theoretical Biol Med Model. 2011;8:20.

41. Gatenby RA, Gillies RJ. Why do cancers have high aerobic glycolysis? Nat Rev Cancer. 2004:4:891-9.

42. Wessells H, Angermeier KW, Elliott S, Gonzalez CM, Kodama R, Peterson AC, Reston J, Rourke K, Stoffel JT, Vanni AJ, Voelzke BB, Zhao L, Santucci RA. Male urethral stricture: American Urological Association guideline. J Urol. 2017:197:182-90.

43. Ram-Liebig G, Bednarz J, Stuerzebecher B, Fahlenkamp D, Barbagli G, Romano G, Balsmeyer U, Spiegeler ME, Liebig S, Knispel H. Regulatory challenges for autologous tissue engineered products on their way from bench to bedside in Europe. Adv Drug Deliv Rev. 2015;82-83:181-91.

44. Liu Y, Ma W, Liu B, Wang Y, Chu J, Xiong G, Shen L, Long C, Lin T, He D, Butnaru D, Alexey L, Zhang Y, Zhang D, Wei G. Urethral reconstruction with autologous urine-derived stem cells seeded in three-dimensional porous small intestinal submucosa in a rabbit model. Stem Cell Res Ther. 2017;8:63.

45. Li CL, Liao WB, Yang SX, Song C, Li YW, Xiong YH, Chen L. Urethral reconstruction using bone marrow mesenchymal stem cell- and smooth muscle cell-seeded bladder acellular matrix. Transplant Proc. 2013:45:3402-7.

46. De Filippo RE, Kornitzer BS, Yoo JJ, Atala A. Penile urethra replacement with autologous cell-seeded tubularized collagen matrices. J Tissue Eng Regen Med. 2015;9:257-64.

47. Pinnagoda K, Larsson HM, Vythilingam G, Vardar E, Engelhardt EM, Thambidorai RC, Hubbell JA, Frey P. Engineered acellular collagen scaffold for endogenous cell guidance, a novel approach in urethral regeneration. Acta Biomater. 2016;43:208-17.

48. Lai Y, Cao H, Wang X, Chen S, Zhang M, Wang N, Yao Z, Dai Y, Xie X, Zhang $P$, Yao $X$, Qin L. Porous composite scaffold incorporating osteogenic phytomolecule icariin for promoting skeletal regeneration in challenging osteonecrotic bone in rabbits. Biomaterials. 2018;153:1-13.

49. Ribeiro VP, da Silva Morais A, Maia FR, Canadas RF, Costa JB, Oliveira AL, Oliveira JM, Reis RL. Combinatory approach for developing silk fibroin scaffolds for cartilage regeneration. Acta Biomater. 2018;72:167-81.

\section{Publisher's Note}

Springer Nature remains neutral with regard to jurisdictional claims in published maps and institutional affiliations.

Ready to submit your research? Choose BMC and benefit from:

- fast, convenient online submission

- thorough peer review by experienced researchers in your field

- rapid publication on acceptance

- support for research data, including large and complex data types

- gold Open Access which fosters wider collaboration and increased citations

- maximum visibility for your research: over $100 \mathrm{M}$ website views per year

At $\mathrm{BMC}$, research is always in progress.

Learn more biomedcentral.com/submission 